\title{
Optimal Microgrid Power Supply System for Nigerian Detached Communities: Environmental Impact and Energy Cost Criteria
}

\author{
J. G. Akinbomi ${ }^{a, *}$, L. C. Ezeilo ${ }^{\text {, O. Fagbuyi }}{ }^{\mathrm{c}}$, L. Onyebueke ${ }^{\mathrm{c}}$ \\ ${ }^{a}$ Department of Chemical Engineering, Lagos State University, Epe Campus, Epe, Lagos State, NIGERIA. \\ ${ }^{b}$ Centre for Environmental Studies and Sustainable Development, Lagos State University, Ojo, Lagos State, \\ NIGERIA.
}

${ }^{c}$ Department of Mechanical and Manufacturing Engineering, College of Engineering, Tennessee State University, 3500 John A. Merritt Boulevard, Nashville TN 37209, USA.

\begin{abstract}
Climate change is a major contemporary global challenge. For developing countries like Nigeria, further challenge is poor power supply. Traditional power supply strategy has been through fossil-fuel based macrogrids. While most developed countries are replacing some macrogrids with renewable energy based microgrids, developing countries like Nigeria still maintain the status quo. This study intends to contribute to knowledge in the management of climate change and power supply in Nigeria through the adoption of microgrids as power supply strategy. In the study, data collected from a detached energy consuming community in Nigeria was used in a simulation using HOMER software for five different scenarios of energy resources combination, based on environmental impact and energy cost criteria. Results indicate that microgrids combining solar photovoltaic (SPV) and grid connection with battery energy storage (BES) are best in on-grid detached communities while microgrids combining diesel generators and SPV with BESare good for off-grid communities.
\end{abstract}

Keywords: microgrids, cost optimization, environmental impact, renewable energy

\section{INTRODUCTION}

The world is currently faced with the challenge of climate change which is largely due to the increased levels of greenhouse gases (GHGs) in the atmosphere as a result of human activities. Among such GHGs is carbon dioxide $\left(\mathrm{CO}_{2}\right)$, which is often emitted from the burning of fossil fuels for electricity generation and other purposes. In most developing countries such as Nigeria, electricity supply is erratic, in that it is not accessible most of the time, and when it is accessible, it may not be within the appropriate voltage specifications. The poor electricity supply in Nigeria is corroborated by data and reports from various sources [1, 2].The quarterly total daily power generation in Nigeria for the period 2015-2018 as computed using data from National Bureau of Statistics website [1] indicated that the daily average power generation during the period varied from lowest value of $2,636 \mathrm{MW}$ in quarter $2 / 2016$ to highest value of $4,112 \mathrm{MW}$ in quarter $4 / 2018$

${ }^{*}$ Corresponding author (Tel: +234 806073 4907)

Email addresses: julius.akinbomi@lasu.edu.ng (J. G. Akinbomi), chuka91@yahoo.com (L. C. Ezeilo), ofagbuyi@my.tnstate.edu (O. Fagbuyi),

lonyebueke@tnstate.edu (L. Onyebueke)
[2]. These are far inadequate to meet the demand of electricity consumers nationwide, resulting in frequent power outages. According to a survey by NOIPolls Limited [2], the annual average cumulative hours of power supply per day for three years 2016, 2017 and 2018 were 8.6, 9.7 and 9.5 hours, respectively, while the highest average daily cumulative hours of power supply to households from January to December 2018 was 10.3 hours. These were extremely low compared to 24 hours daily power availability in most countries of the world [2].

Nigeria meets its energy needs through four main sources namely coal, hydro, oil and natural gas in the proportions of about $0.4 \%, 35.6 \%$, $24.8 \%$ and $39.8 \%$ respectively, but despite its endowment with large oil, coal, gas, hydro and solar resources, it was rated second worst country in the world in power supply [3, 4]. Nigeria's electric power generation capacity was $12.5 \mathrm{GW}$ from existing plants [4]. Unfortunately, the existing power transmission facilities can only transmit 3500-5000 MW which is insufficient $[4,5]$. Consequently, electricity distribution companies are unable to provide sufficient power to rural areas and most urban cities due to low generation capacity and underdeveloped transmission and distribution networks. Over 100 million Nigerians 
had no access to electricity from the grid and those who were connected to the grid experienced frequent power interruptions [6,7]. In Nigeria, the average electrical energy consumption per capita in the 1971-2014 period was about $89 \mathrm{kWh}$ with maximum and minimum of $157 \mathrm{kWh}$ and $29 \mathrm{kWh}$ reported in 2012 and 1971 respectively. This is far below the global minimum average electricity consumption per capita of $500 \mathrm{kWh}$ for developing economies. Based on a rule of thumb estimate, an industrial nation requires $1,000 \mathrm{MW}$ per million inhabitants [6]. Nigeria with a population of over 200 million people should therefore be targeting about $200,000 \mathrm{MW}$ of electricity generation if it aspires to attain industrialized nation status. To establish that there is huge energy supply gap in Nigeria; energy modeling tools including Model for the Analysis of Energy Demand (MAED) and Model for the Energy Supply Strategy Alternatives and their General Environment Impact (MESSAGE) for energy demand and supply, respectively, were used with basis on a gross domestic product (GDP) of $7 \%$ for Nigeria [5]. Nigeria's projected energy demand and supply for 2020 were estimated to be $50,820 \mathrm{MW}$ and $50,817 \mathrm{MW}$, respectively.

In a related perspective, the world today is faced with the problem of climate change caused by human activities among which is electricity generation from fossil fuels that results to increased carbon dioxide emission into the atmosphere. As earlier stated, many developing countries including Nigeria have problems meeting their electricity needs and rely heavily on fossil fuels for electricity generation. In Lagos, Nigeria, the challenge of pressing housing needs necessitates various efforts by government and estate developers to implement housing policies to provide comfortable housing for the teeming population. Among these efforts is the development of isolated or detached residential estates in emerging new areas of the mega city. These estates are provided with necessary infrastructure including utility supplies. However, there is little, if any, coordination between the estate developers and the utility providers, particularly in respect of power supply. Thus, power supply in the estates is generally from a set of diesel or natural gas (rarely) power plants operated by the estate owner or manager or an independent power provider (IPP), and may not be connected to the national grid due to the non-reliability of electricity supply from the grid. The charges for electricity in such estates are usually far higher than that by the national utility due to very high production costs and the need to ensure steady availability.Aside from electricity supplies in detached residential estates, there are also remote village communities in Lagos and in other parts of Nigeria that are not connected to the national electricity grid. As a result, residents of such villages either live without electricity or rely on small household generating sets that burn highly inflammable petrol, or diesel. The risks inherent in these practices are enormous. For example, there have been several cases of extermination of entire or part of households by fire or carbon monoxide from the small electricity generators. Aside from residential estates and village communities not connected to the national electricity grid, there are industrial units and other detached communities or establishments like agricultural settlements, educational institutions, among others, that may not be connected to the national grid but need reliable electricity. These communities presently resort to use of owner operated or IPP diesel (fossil fuel) based power plants.

In all the above cases, power supply is provided by natural gas or diesel or petrol engine-based electricity generators at very high negative environmental impact and cost. This suggests that there is a knowledge gap for a practical model for the provision of power supply from alternative renewable energy sources like solar energy, despite its limitless abundance, free availability and little or no negative environmental impact. The idea of introduction of renewable energy sources into the Nigerian energy mix to solve the country's energy challenges has received attention lately [3]. The Federal Government has provided appropriate legal platform for use of renewable energy in Nigeria through the National Renewable Energy Master plan (NREMP) initiated in 2006 with overall objective to articulate a roadmap for national development through accelerated development and exploitation of renewable energy [8]. The Federal government also supported sustainable alternative off-grid power supply as part of strategies to solve Nigeria's perennial power challenge through a legal framework known as the Nigerian Electricity Regulatory Commission (NERC) Minigrid Regulation 2016, established under Part III of the Electric Power Sector Reform Act 2005, and empowered to regulate the Nigeria Electricity Supply Industry (NESI). [7] had also recommended Minigrid strategy as an innovative way to solve Nigeria's power supply problem especially in rural areas.

Microgridis an integrated system comprising distributed energy resources (energy generation and storage), interconnected loads, and control system, with clearly defined electrical boundary and acts as a single controllable entity with respect to the grid and can connect or disconnect from it [9-11]. The microgrid is a subsystem of a main electricity supply system with its own electrical boundary; it is an intentional power supply island either at a customer's facility or a location that incorporates parts of the local utility with at least one distributed energy resource and associated loads and can operate in grid-tied (synchronous) mode or is landed (autonomous) mode, without shortage or compromising power quality, and may include renewable energy resources and energy storage [12-15]. In microgrids system, the power generation resources and loads are often within short distance which helps to reduce transmission losses [16]. The main components of a microgrid system include Energy Supply System, Energy Storage System, Demand Response and 
Efficiency Measures, Energy Management Systems and Utility [9]. Microgrid is strategy, with its low dependence on transmission and distribution facilities, can provide additional benefits to the local utility by providing dispatchable power for use during peak power conditions and alleviating or postponing distribution system upgrades [17-19]. Aside from contributing to solving Nigeria's power supply challenge, adoption of microgrids with high renewable energy penetration will enable Nigeria conform to the global need to reduce GHGs emission to protect the environment.

Regarding the application of microgrids strategy, off-grid solar Photovoltaic (PV) systems had been recommended as the best solution for off-grid electrification in rural Sumba Island, Indonesia [20]. This rural area is an electricity consuming community similar to some rural settings in Nigeria for which this study is expected to be useful. Despite the availability of solar power resources in Nigeria, solar PV installation is limited and scanty in the country. Renewable energy technologies had not significantly penetrated the energy scene of Nigeria's South-East zone and solar photovoltaic was the only renewable energy application in use [21]. The situations could also be related to other parts of Nigeria. According to a study by [22], Nigeria is richly endowed with solar energy with an annual average daily sunshine of 6.5 hours, ranging from 4 hours at the coastal areas to 9 hours at the far northern boundary. Nigeria receives an average solar radiation of $3.5 \mathrm{kWh} / \mathrm{m}^{2}$ daily at the coastal latitudes and $7 \mathrm{kWh} / \mathrm{m}^{2}$ daily at the far north [22]. Therefore, solar radiation is viable for electricity generation in every location in Nigeria if the right technology is put in place [22].

There are many research works on microgrids despite its being a relatively new field of interest. This is in part due to its potential to contribute to global efforts to combat climate change by reducing greenhouse gas emission through high penetration of renewable energy generation sources. Following a detailed review of research works on microgrids in Nigeria, a number of research gaps were identified, among which are environmental impact and energy cost optimization. Consequently, this study is focused on these two areas - environmental impact and energy cost optimization criteria - as they affect the selection of optimal power supply strategy in Nigeria.

The main objective of the study is to identify a power supply strategy that will have lower adverse environmental impact and cost compared to the current power supply strategy. This is important in the reduction of greenhouse gases emission as well as the provision of sustainable solution to the current persistent electricity deficit in Nigeria. This study will focus on Hybrid Energy model with solar photovoltaic (PV), wind turbine and battery storage since they are the most common renewable distributed generation resources (DGRs). The model will be adaptable for use in detached or isolated communities in Nigeria, such as residential estates in Lagos, which may or may not have grid connection. The scope of this study covers the use of microgrids strategy with high solar and wind turbine penetration with energy storage. It does not include investigation of other forms of renewable energy, control strategy for the microgrids system, measurement of weather data of the location hosting the microgrids as well as detailed study of the extent and causes of power supply deficit in Nigeria.

\section{METHODS AND MATERIALS}

This study is an applied technique research as it aims to contribute to the development of better strategy for providing power supply with low emission of environmental pollutants. As a result of the nature of the study, quasi-experimental research design was used. An existing power supply system (diesel power plant) in a typical detached energy consuming community, namely, Lagos State University, Epe Campus, Lagos State, Nigeria, was used as a case study for field data collection.Lagos State University, Epe Campus uses mainly two diesel generators (capacities 250kVA and 400kVA) for its power supply. Although connected to the national grid, it relies mainly on own power generation due to unreliability of grid supply as grid power is not available most of the time. The major energy loads include electrical gadgets in offices, lecture rooms, research laboratories and workshops, students' hostels, staff quarters, as well as commercial shops and business centres within the university community. Hence power consumption is spread through 24 hours of the day, although with shifting peak demand patterns from one area to another during different times (morning, noon and night).

The data needed for the study included power consumption (load) profile for the energy consuming community, annual hourly average solar irradiation and clearness index for the city (Lagos), annual monthly average wind speed data for the city (Lagos), prices of microgrids components and price of diesel. Daily hourly total current output from the diesel generating sets for three months (January 1 to March 31, 2019) were collated from hourly current (load) log sheets recorded directly from the instrument panel of the generating sets. These readings were taken on 24hour basis by operators on 2-shift per day work of day and night shifts. The accuracy of power profile data was enhanced through widespread collection for a 3-month period covering low and high activity periods (full academic period and a period when students were not in school). The hourly data recorded on power log sheets were collated and entered into a Microsoft excel spreadsheet which calculated average hourly power output to get a load profile. A specialized software tool, HOMER software for microgrids design, was used with the computed hourly power outputs to simulate power supply scenarios to satisfy the loads based on different strategies. Five electricity supply strategies were simulated including Strategy 
1 (DG+BS): Diesel Generator and Battery Storage (Control); Strategy 2 (DG+WT+BS): Diesel Generator, Wind Turbine and Battery; Strategy 3(DG+PV+BS):Diesel Generator, Solar PV system and Battery; Strategy 4 (DG+Grd):Diesel Generator and Grid connection (Existing Strategy) and Strategy 5 (PV+Grd+BS): Solar PV system, Grid connection and Battery.

Other inputs were also incorporated into the software for the simulation. For example, open market prices of various microgrids components (diesel generating set, solar photovoltaic panels, wind turbine, rechargeable batteries, bidirectional inverter and load controller) were obtained from proforma invoices from local dealers on the components that were locally available. However, wind turbine price was obtained from the U.S.A. market as no local price could be obtained. Open market price of diesel in Nigeria was used. Exchange rate of NGN360/US\$ was used for currency conversion. Other data - annual hourly weather data (average hourly solar insolation and average monthly wind speeds) - were from HOMER software data base which is used globally by all HOMER software users. Average hourly solar irradiation, clearness index and wind speeds for Lagos in HOMER software database were used as HOMER hosts required weather data for major cities in the world (Table 1). The required weather data for Lagos were entered appropriately and the HOMER software used the weather data with the imputed field data to run an optimization simulation and generated optimization results report. The hourly power output from each of the three phases of the generator was calculated on Microsoft Excel based on Eq. (1).

$$
P=V \times I \times P F
$$

where $P$ is Power $(\mathrm{kW}), V$ is line voltage $(\mathrm{V})$, $I$ is line current (amps) and $P F$ is power factor. The total hourly power output is the sum of the hourly power outputs for the three phases. Regarding Solar photovoltaic (PV) Array Power Output, HOMER calculated the output using Eq. (2) (without modeling the effect of temperature on the PV array which was the case in this study for simplicity) [23].

$$
P_{P V}=Y_{P V} f_{P V}\left[\frac{\bar{G}_{T}}{\bar{G}_{T, S T C}}\right]
$$

where $Y_{P V}$ is the rate capacity of the PV array, meaning its power output under standard test conditions $(\mathrm{kW}) ; f_{P V}$ is the PV derating factor [\%]; $\bar{G}_{T}$ is the solar radiation incident on the PV array; and $\bar{G}_{T, S C}$ is the incident radiation at standard test conditions $\left[1 \mathrm{~kW} / \mathrm{m}^{2}\right]$.

For the Wind Turbine Power Output, HOMER calculated the power output of the wind turbine in each time step using a three-step process. First, HOMER calculated the wind speed at the hub height of the wind turbine. Then it calculated how much power the wind turbine produces at that wind speed at standard air density. Finally, HOMER adjusted that power output value for the actual air density.In each time step, the HOMER software calculates the wind speed at the hub height of the wind turbine using the inputs in the Wind Resource page and the Wind Shear entry. In this study, the model of wind power output based on the power law was used [23]. Based on the power law, HOMER calculated the hub height wind speed using Eq. (3).

$$
U_{\text {hub }}=U_{\text {anem }}\left(\frac{Z_{\text {hum }}}{Z_{\text {anem }}}\right)^{\alpha}
$$

where $U_{h u b}$ is the wind speed at the hub height of the wind turbine $(\mathrm{m} / \mathrm{s}) ; U_{\text {anem }}$ is the wind speed at anenometer height $(\mathrm{m} / \mathrm{s}) ; Z_{h u b}$ is the hub height of the wind turbine $(\mathrm{m}) ; z_{\text {anem }}$ is the anenometer height $(\mathrm{m})$ and $\alpha$ is the power law exponent. After determining the hub height wind speed, the HOMER software used the wind turbine power curve to calculate the expected power output from the wind turbine at that wind speed under standard conditions of temperature and pressure. Since the Power curves typically specify wind turbine performance under conditions of standard temperature and pressure (STP), the software used the air density ratio to multiply the power value predicted by the power curve in order to adjust to actual conditions (Eq. (4)).

$$
P_{W T G}=\left(\frac{\rho}{\rho_{0}}\right) \times P_{W T G, S T P}
$$

where $P_{W T G}$ is the wind turbine power output $(\mathrm{kW}) ; P_{W T G, S T P}$ is the wind turbine power output at standard temperature and pressure $[\mathrm{kW}]$; $\rho$ is the actual air density $[\mathrm{kg} / \mathrm{m} 3]$; and $\rho_{0}$ is the air density at standard temperature and pressure $(1.225 \mathrm{~kg} / \mathrm{m} 3)$.

As regards calculation of generator emissions (pollutants), the emissions factor (kg of pollutant emitted per unit of fuel consumed) for each pollutant was determined using the HOMER softwarebefore simulating the power system [24]. After the simulation, the software estimated the annual emissions of that pollutant by multiplying the emissions factor by the total annual fuel consumption. The emissions factors for four of the six pollutants(carbon monoxide, unburned hydrocarbons, particulate matter, and nitrogen oxides) were specified as inputs by the software. Using these values along with the carbon and sulfur contents of the fuel, HOMER software calculated the emissions factors for the two remaining pollutants which are carbon dioxide and sulphur dioxide. The estimation of the emission factors was based on three principal assumptions: any carbon in the fuel not emitted as carbon monoxide or an unburned hydrocarbon was emitted as carbon dioxide, the carbon fraction of the unburned hydrocarbon emissions was the same as that of the fuel, and any sulfur in the burned fuel that was not emitted as particulate matter was emitted as sulphur dioxide. 


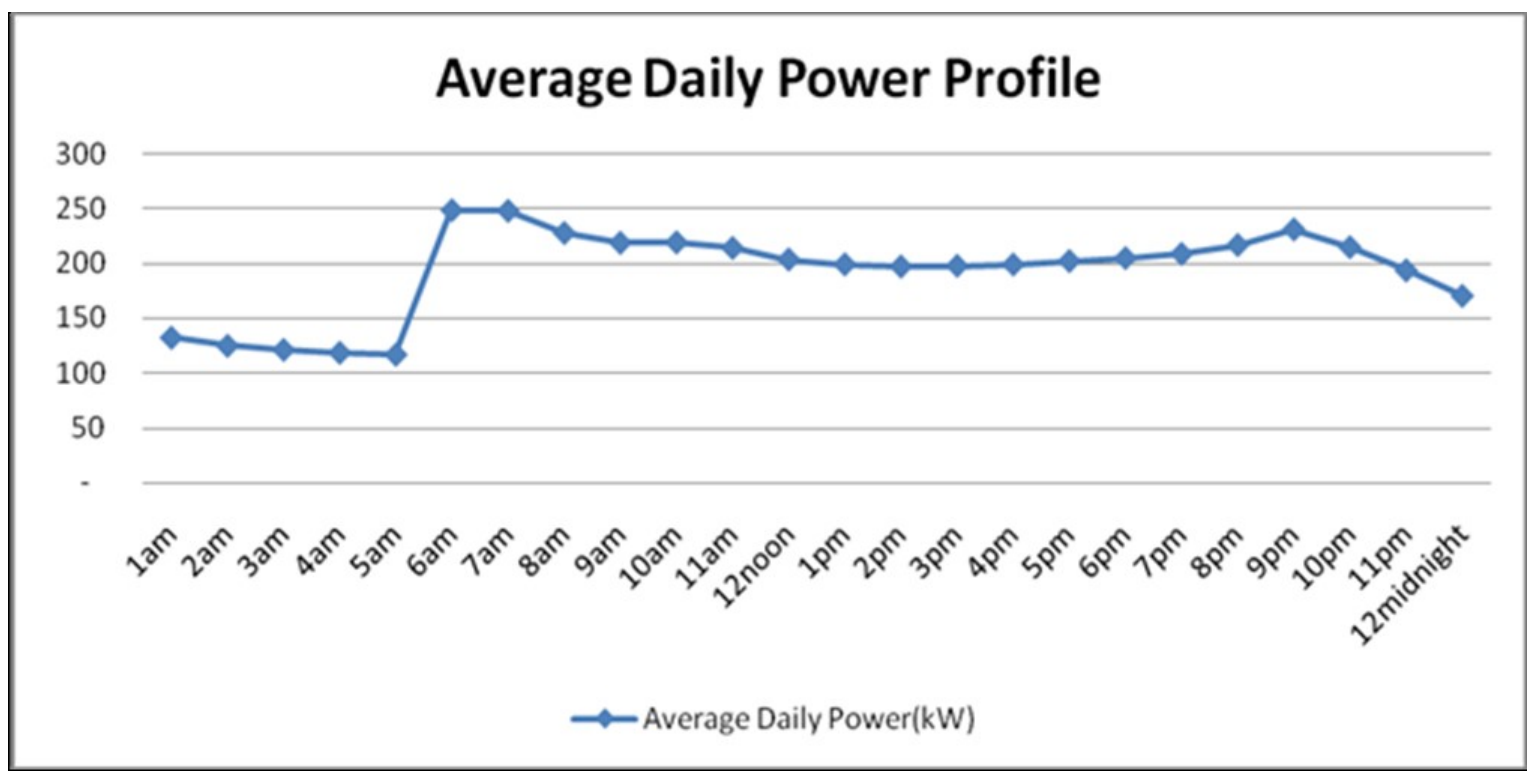

Figure 1: Average daily power profile.

Furthermore, HOMER software calculated the Levelized Cost of Energy (LCOE)which is defined as the average cost per $\mathrm{kWh}$ of useful electrical energy produced by the system. The LCOE was calculated by [24] by dividingthe annualized cost of producing electricity by the total electric load served (Eq. (5)).

$$
L C O E=\frac{C_{a n n, t o t}}{E_{\text {served }}}
$$

where $C_{a n n, t o t}=$ total annualized cost of the system $[\$ / \mathrm{yr}]$; and $E_{\text {served }}$ is the total electrical load served $[\mathrm{kWh} / \mathrm{yr}]$.

The modeled components along with their design details used in the HOMER modeling included Solar PV system - Generic Flat Plate (Initial capital: $\$ 215 / 250 \mathrm{~W}$; Replacement: \$215/250W; Operation and maintenance: \$15/year), Wind turbine-VergnetGEV MP-R 275kW (Initial capital: $\$ 350,000$; Replacement: $\$ 300,000$; Operation and maintenance: $\$ 7,000 /$ year),Lithium-ion battery -202Ah, 10.5kWh 52V (Initial capital: \$375; Replacement: $\$ 375$;Operation and maintenance: \$10/year), Diesel generator - CAT 400kVA $50 \mathrm{~Hz}$ (Initial capital: $\$ 63,000$;Replacement: $\$ 63,000$; Operation and maintenance: \$6.5/op.hr; Fuel price: $\$ 0.71 / \mathrm{L}$ ), Grid connection (Fixed electricity tariff: $\$ 0.12 / \mathrm{kWh}$; Average hours of grid power availability per day: $10 \mathrm{hrs}$ (2am-8am and $4 \mathrm{pm}$ - 8pm);Converters and Charge controllers 60A/48V (Initial capital: \$145. Operation and maintenance: $\$ 15 /$ year).

For the modeled scenarios, the five combinations of components modeled in the simulation were Strategy 1 (DG+BS): Diesel Generator and Battery Storag (Control); Strategy 2 (DG+WT+BS): Diesel Generator, Wind Turbine and Battery; Strategy 3(DG+PV+BS): Diesel Gen- erator, Solar PV system and Battery; Strategy 4 (DG+Grd):Diesel Generator and Grid connection (Existing Strategy) and Strategy $5(\mathrm{PV}+\mathrm{Grd}+\mathrm{BS})$ : Solar PV system, Grid connection and Battery.The independent variable in this study was electricity supply strategy while the dependent variables are electricity supply cost and environmental impact $\left(\mathrm{CO}_{2}\right.$ emission). The effect of the independent variable on the dependent variables was monitored by choosing combinations of power supply components (different power supply strategies) that result to different values of each of the dependent variables. The strategy (combination of power supply components) that yielded optimal values of the dependent variables (lowest $\mathrm{CO}_{2}$ emissions and lowest electricity cost) while meeting the power supply demand was the winning strategy.

\section{RESULTS AND DISCUSSION}

Regarding power consumption data, Fig. 1 shows the average daily power output(load) profile from the daily hourly total current output from two diesel generators (capacities $250 \mathrm{kVA}$ and 400kVA) for three months (January 1 to March 31, 2019) in Lagos State University, Epe Campus, Lagos State, Nigeria.The weather data from HOMER software database used for the modeling are presented in Table 1. In the design analysis, the basis used by the HOMER software in assessing the results were Net Present Cost (NPC), Operating Cost (OpCost), Levelized Cost of Energy (LCOE), Fuel Consumption Rate (FCR), Emissions (Pollutants penetration) $\left(\mathrm{EmCO}_{2}\right)$, Excess Electricity (ExcElect), Discounted Payback Period (DPP), Project Lifetime (15, 20 and 25years). Based on the objective of this study with focus on environmental impact and energy cost, the criteria pertaining to only these two variables were analyzed. For environmental impact, these are Fuel Consumption Rate (FCR) andEmissions 
Table 1: Weather data used for modelingfrom HOMER software database.

\begin{tabular}{|c|c|c|c|}
\hline Month & Clearness Index & $\begin{array}{l}\text { Solar Energy } \\
\text { Daily Radiation }\left(\mathrm{kWh} / \mathrm{m}^{2} / \text { day }\right)\end{array}$ & Average Wind Speed $(\mathrm{m} / \mathrm{s})$ \\
\hline January & 0.567 & 5.280 & 4.150 \\
\hline February & 0.556 & 5.490 & 4.300 \\
\hline March & 0.527 & 5.460 & 4.010 \\
\hline April & 0.499 & 5.210 & 3.490 \\
\hline May & 0.467 & 4.760 & 3.000 \\
\hline June & 0.405 & 4.040 & 3.120 \\
\hline July & 0.303 & 3.950 & 3.700 \\
\hline August & 0.387 & 3.980 & 3.870 \\
\hline September & 0.396 & $\begin{array}{l}0.500 \\
4.090\end{array}$ & 3.500 \\
\hline October & 0.457 & 4.550 & 2.830 \\
\hline November & 0.527 & 4.950 & 3.050 \\
\hline December & 0.569 & 5.170 & 3.650 \\
\hline
\end{tabular}

Source [24]

Table 2: Simulation results for emissions (pollutants).

\begin{tabular}{|c|c|c|c|c|}
\hline $\mathbf{S} / \mathbf{N}$ & & Carbon dioxide (Kg/yr) & Carbon monoxide $(\mathrm{Kg} / \mathrm{yr})$ & Unburnt hydrocarbons $(\mathrm{Kg} / \mathrm{yr})$ \\
\hline 1 & $\mathrm{DG}+\mathrm{BS}$ & 50,475 & 76.3 & 0.574 \\
\hline 2 & $\mathrm{DG}+\mathrm{WT}+\mathrm{BS}$ & 21,659 & 32.7 & 0.246 \\
\hline 3 & $\mathrm{DG}+\mathrm{PV}+\mathrm{BS}$ & 9,339 & 14.1 & 0.106 \\
\hline 4 & $\mathrm{DG}+\mathrm{Grd}$ & 398,490 & 585 & 4.40 \\
\hline 5 & $\mathrm{PV}+\mathrm{Grd}+\mathrm{BS}$ & 33 & 0 & 0 \\
\hline
\end{tabular}

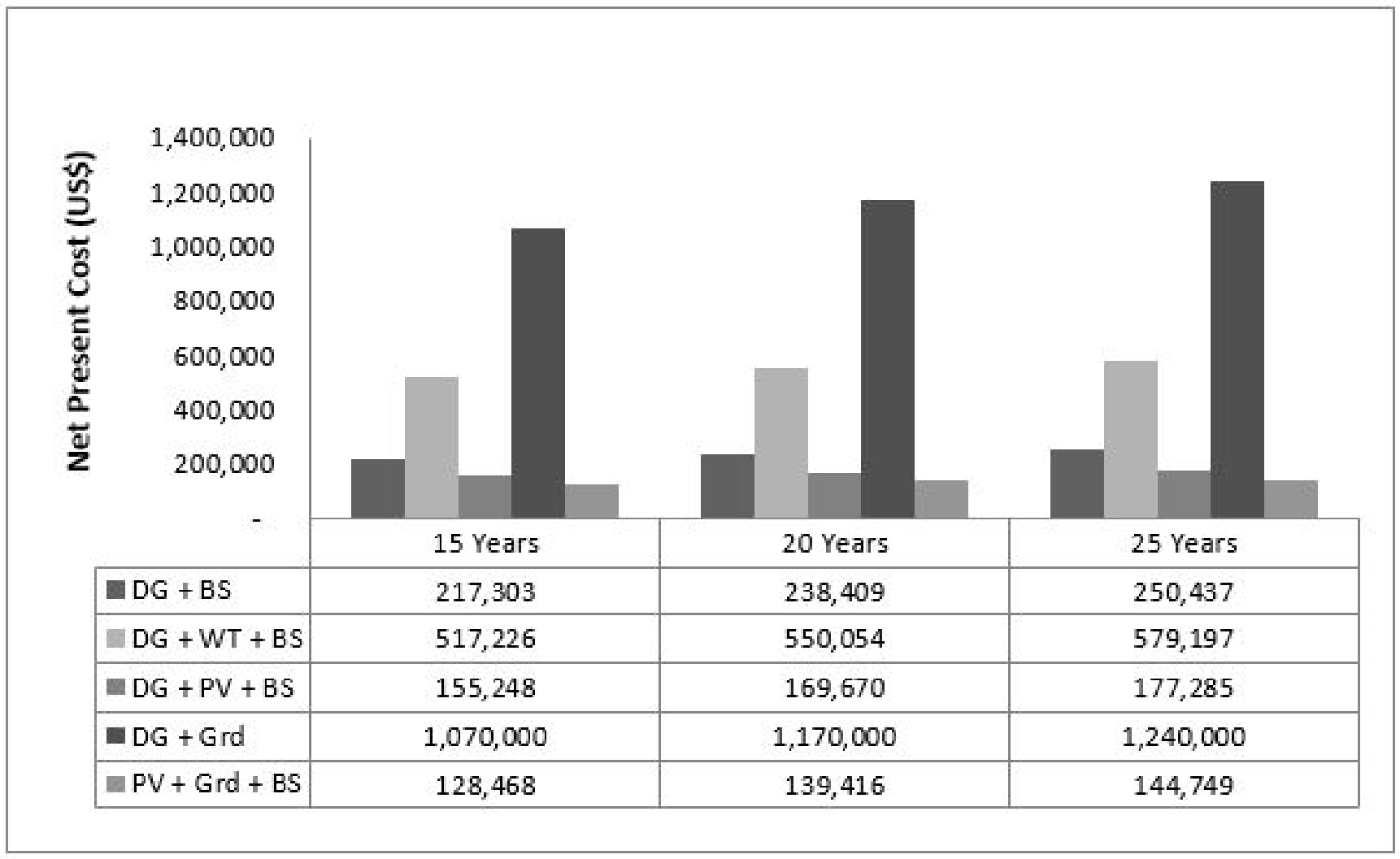

Figure 2: Simulation results for net present cost. 


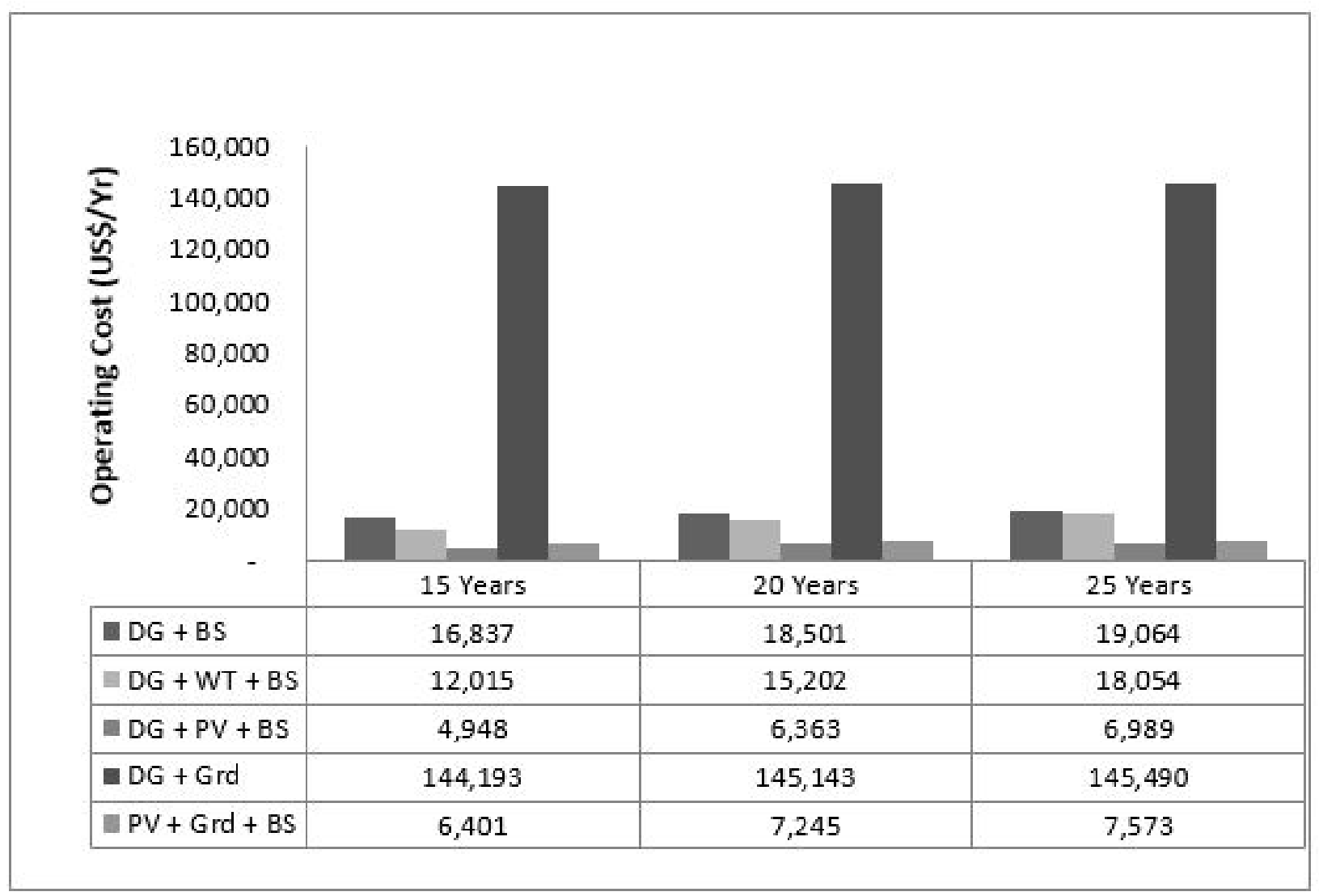

Figure 3: Simulation results for operating cost.

(pollutants penetration), including Carbon Dioxide (EmCO2), Carbon Monoxide (EmCO) and Unburnt Hydrocarbons (EmUnbH/Carbon). For energy cost, the criteria include Net Present Cost (NPC), Operating Cost (OpCost) and Levelized Cost of Energy (LCOE). For these criteria, the design analysis results for the project life time scenarios of 15 years, 20 years and 25 years have identical trends and are presented in Figs. 2 to 5 and Table 2 while the analyzed data were presented in Tables 3 and 4.

In the selection of optimal strategy based on the simulation results, power supply strategy that has lower energy cost and lower adverse environmental impact compared to the current strategy (of power supply from diesel generators and grid: DG + Grd) will be preferred, in line with the main objective of the study.Looking at both Tables 3 and 4 , it can be seen that strategy 5 - Solar PV and grid connection with battery storage (PV + Grd + BS)is the winning strategy.From same Tables 3 and4, strategy 3 -Diesel Generator and solar PV with Battery Storage $(D G+P V+B S)$ is the second; strategy 2 - Diesel Generator and Wind Turbine with Battery Storage (DG + WT + BS) is the third considering environmental impact (Table 4) but fourth considering energy cost (Table 3 ) while strategy 4 - Diesel Generator and Grid connection only which is the current strategy is the worst option considering both cost and environmental impact.
It is worthy of mention that in considering the most environmentally friendly power supply strategy, fuel consumption rate and level of emissions (pollutants) were used as the determinants. Emission is closely related to fuel consumption, since diesel combustion directly results to $\mathrm{CO}_{2}$ and other gaseous and particulate matter emissions. Table 5 shows the summary of the components as well as the cost of the winning microgrids strategy (Solar PV system, Grid connection and Battery energy storage).

\section{CONCLUSIONS}

In this research work, the application of microgrids strategy in contributing to solving the global challenge of climate change, as well as Nigeria's perennial poor power supply problem was studied, with focus on detached or isolated energy consuming communities in Lagos, Nigeria.

From the study, each of the microgrids power supply strategies considered was more environmentally friendly and cost effective than the existing strategy of combined grid connection and diesel generator power supply. The most environmentally friendly and cost effective was found to be electricity supply through microgrids strategy with Solar PV and Grid connection with Battery storage. This strategy would be the best option where grid supply is available, for example, in detached estates in Lagos that presently use grid supply with diesel generator. Grid connection is attractive (when it is available) due to 
Table 3: Ranked scores of modeling results for energy cost optimization.

\begin{tabular}{llllllc}
\hline S/No. & Strategy & NPC & Op. Cost & LCOE & Sum of Scores & Overall Rank \\
\hline 1 & DG + BS & 3 & 4 & 3 & 10 & 3rd \\
2 & DG + WT + BS & 4 & 3 & 4 & 11 & 4 th \\
3 & DG + PV + BS & 2 & 1 & 2 & 5 & 2 d \\
4 & DG + Grd & 55 & 5 & 15 & 5 th & 1st \\
5 & PV + Grd +BS & 1 & 2 & 1 & 4 & \\
\hline
\end{tabular}

Winning Strategy: Strategy 5 - PV + Grd + BS

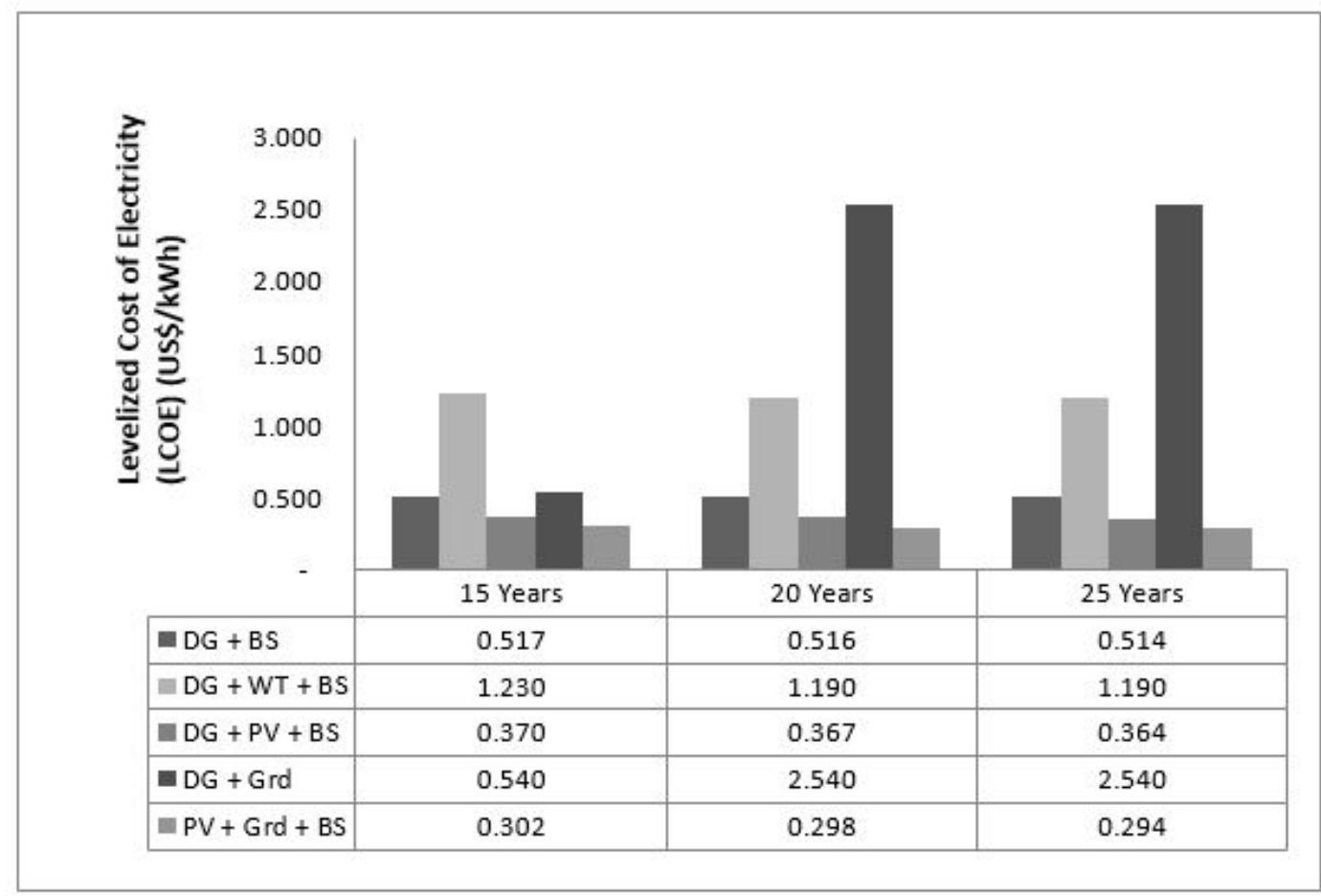

Figure 4: Simulation results for levelized cost of energy.

Table 4: Ranked scores of modeling results for emissions.

\begin{tabular}{|c|c|c|c|c|c|c|c|}
\hline \multirow[b]{2}{*}{ S/No } & \multirow[b]{2}{*}{ Strategy } & \multirow{2}{*}{$\begin{array}{c}\text { Fuel Consumption } \\
\text { Rate }\end{array}$} & \multicolumn{3}{|c|}{ Emissions } & \multirow{2}{*}{$\begin{array}{l}\text { Sum of } \\
\text { Scores }\end{array}$} & \multirow{2}{*}{ Overall Rank } \\
\hline & & & $\begin{array}{l}\text { Carbon } \\
\text { Dioxide }\end{array}$ & $\begin{array}{c}\text { Carbon } \\
\text { Monoxide }\end{array}$ & $\begin{array}{c}\text { Unburnt. } \\
\text { Hydrocarbon }\end{array}$ & & \\
\hline 1 & $\mathrm{DG}+\mathrm{BS}$ & 4 & 4 & 4 & 4 & 16 & 4 th \\
\hline 2 & $\mathrm{DG}+\mathrm{WT}+\mathrm{BS}$ & 3 & 3 & 3 & 3 & 12 & $3 r d$ \\
\hline 3 & $\mathrm{DG}+\mathrm{PV}+\mathrm{BS}$ & 2 & 2 & 2 & 2 & 8 & 2nd \\
\hline 4 & $\mathrm{DG}+\mathrm{Grd}$ & 5 & 5 & 5 & 5 & 20 & 5 th \\
\hline 5 & $\mathrm{PV}+\mathrm{Grd}+\mathrm{BS}$ & 1 & 1 & 1 & 1 & 4 & $1 \mathrm{st}$ \\
\hline
\end{tabular}

Winning Strategy: Strategy 5 - PV + Grd + BS

Table 5: Cost summary of the winning microgrids strategy (Solar PV system, grid connection and battery Storage) from the HOMER modeling.

\begin{tabular}{llllll}
\hline Component & Capital $(\$)$ & Replacement $(\$)$ & $\begin{array}{l}\text { Operation \& } \\
\text { Maintenance }(\$)\end{array}$ & Salvage $(\$)$ & Total $(\$)$ \\
& & & $19,533.01$ & $3,412.35$ & $47,878.44$ \\
202Ah Lithium ion battery & $20,250.00$ & $4,683.08$ & $28,035.60$ & $4,450.05$ & $90,253.35$ \\
Solar PV Plates & $57,767.70$ & 0.00 & 43.81 & 0.00 & 43.81 \\
Grid connection & 0.00 & 0.00 & 104.34 & 0.00 & 249.34 \\
Charge controller & 145.00 & 0.00 & 0.00 & 0.00 & $5,774.98$ \\
Converter & $5,774.98$ & 0.00 & $47,716.77$ & $7,862.40$ & $144,199.92$ \\
System (Total) & $83,937.68$ & $4,683.08$ & &
\end{tabular}




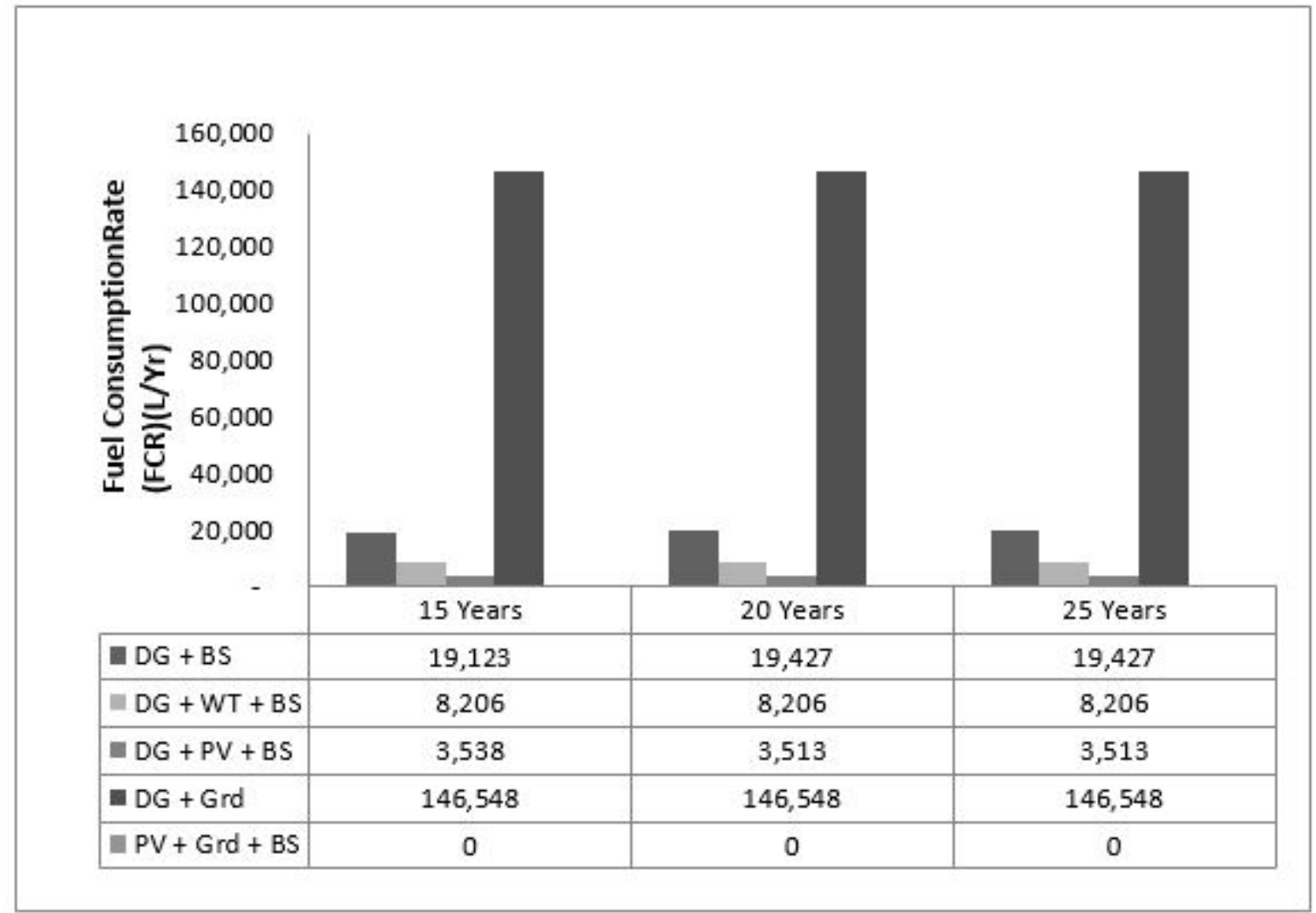

Figure 5: Simulation results for fuel consumption rate.

low grid electricity cost. The strategies involving Diesel Generator and Solar PV with Battery Storage which is second from the study) and Diesel Generator and Wind Turbine with Battery Storage (which is third from the study) would be suitable for energy consuming communities without grid availability - like remote villages with abundant sunshine and wind resources.

Based on the findings from this study, it is recommended that microgrids power supply strategy be adopted in Lagos both in non-detached and detached energy consuming communities. The strategy is also recommended to be incorporated in the national electricity power supply policy for nation-wide implementation in the medium and long-term planning periods in order to comply and contribute to the global efforts to combat climate change as well as to rescue Nigeria from the current perennial power supply challenges.

\section{ACKNOWLEDGEMENT}

The authors appreciate the Management and staff of Department of Works, Lagos State University, Epe Campus, Epe, Lagos State University for their assistance in data acquisition.
Abbreviatiions
DER - Distributed Energy Resource
DGR - Distributed Generation Resource
IPP - Independent Power Provider
MW - Megawatt(s)
NBS - National Bureau of Statistics

NEPP - National Electric Power Policy

NERC - Nigeria Electricity Regulatory Commission

NESI - Nigeria Electricity Supply Industry

\section{References}

[1] (2019, March) Power sector repor:power generation statistics - daily energy produced and sent out. National Bureau of Statistics/Nigerian Electricity Regulatory Commission (2015-2019). [Online]. Available: https://nigerianstat.gov.ng/elibrary

[2] (2019, March) Noipolls 2018 power supply tracking; power supply to nigerian households still inadequate. NOIPolls Limited. [Online]. Available: https://www. noi-polls.com

[3] G. Ibenegbu. (2018, March) Poor power supply in nigeria: what is the reason? NOIPolls Limited. [Online]. Available: https://www.legit. ng/1170127-poor-power-supply-nigeria-reason.html\# 1170127

[4] N. E. S. Overview. (2021, March) USAID Nigeria Power Africa Factsheet. [Online]. Available: https: //2012-2017.usaid.gov/powerafrica/nigeria

[5] A. Okoye, "Review of nigeria power sector," University of Nigeria, Nsukka, Tech. Rep. 001, 2014. [Online]. Available: https://doi.org/10.13140/2.1.3509.9849

[6] "Nigerian power sector: Is there light at the end of the tunnel? nigerian power sector report - february 2017," United Capital, Power Sector Report, 2019. [Online]. Available: http://www. unitedcapitalplcgroup.com/wp-content/uploads/2017/ 02/United-Capital-Nigeria-Power-Sector-Report-2017. pdf

[7] "Outages as nigeria's power grid drops to 4,000mw," Energy Mix Report, March 2019. [Online]. Available: https://www.energymixreport.com/ outages-as-nigerias-power-grid-drops-to- $4000 \mathrm{mw} /$

[8] A. Sambo, "Strategic developments in renewable energy 
in Nigeria," International Association for Energy Economics, 2009.

[9] Y. Liu, "Microgrid - future of the power system?" https://www.ewh.ieee.org/r6/san_francisco/pes/pes_pdf /SFPES_Microgrids_Nov_2014.pdf, 2019.

[10] S. Parhizi, H. Lotfi, A. Ǩhodaei, and S. Bahramirad, "State of the art in research on micro grids: A review," IEEE Access, vol. 3, no. 2443119, pp. 890-925, 2015.

[11] Department of Energy Office of Electricity Delivery and Energy Reliability., Summary Report: 2012.DOE Microgrid Workshop, Sept 2019.

[12] B. Kroposki, T. Basso, and R. lasio, "Microgrid standards and technologies," in IEEE Power and Energy Society General Meeting - Conversion and Delivery of Electrical Energy in the 21st Century, , Pittsburgh, PA, 2008, pp. 1-4.

[13] S. Wang, Z. Li, Q. Xu, and Z. Li, "Reliability analysis of distributed system with DGs," in 4th International Conference on Electric Utility Deregulation and Restructuring and Power Technologies (DRPT), Weihai, Shandong, 2011, pp. 14-17.

[14] S. Sivachandran and R. Muthukumar, "An overview of microgrid system," International Journal of Applied Engineering Research, vol. 9, no. 22, pp. $12353-$ 12376 , Sept. 2019. [Online]. Available: http://www. ripublication.com

[15] L. Mariam, M. Basu, and M. Conlon, "A review of existing microgrid architectures," Journal of Engineering, pp. 1-8, 2013. [Online]. Available: https://doi.org/10.1155/2013/937614

[16] E. Hossain, E. Kabalci, R. Bayindir, and R. Perez, "A comprehensive study on microgrid technology," International Journal of Renewable Energy Research, vol. 4, no. 4, pp. 1094-1107, 2014.

[17] N. Hatziargyriou, A. Anastasiadis, A. Tsikalakis, and J. Vasiljevska, "Quantification of economic, environmental and operational benefits due to significant penetration of microgrids in a typical LV and MV greek network," European Transactions On Electrical Power, vol. 21, pp. 1217-1237, 2011. [Online]. Available: https://doi.org/10.1002/etep.392

[18] H. Gil and G. andJoos, "The quantification of the network capacity deferral value of distributed generation," European Transactions On Electrical Power, vol. 21, no. 4, pp. 1592-1599, 2006.

[19] N. Hatziargyriou, A. Asano, R. Iravani, and C. Marnay, "Microgrids," Power and Energy Magazine, IEEE, vol. 5, no. 4, pp. 78-94, 2007.

[20] D. Sasetyaningtyas. (2019, Sept.) Sustainable business model for off-grid PV electrification in developing country: In the case of Sumba Island, Indonesia. [Online]. Available: http://resolver.tudelft.nl/uuid: 685ac786-71f0-4e90-9930-d7101591ad5e

[21] C. Uzoma, C. Nnaji, C. Ibeto, C. Okpara, O. Nwoke, I. Obi, G. Unachukwu, and O. Oparaku, "Renewable energy penetration in Nigeria: A study of the South-East Zone," Continental J. Environmental Sciences, vol. 5, no. 1, pp. 1-5, March 2019.

[22] M. Akorede, O. Ibrahim, S. Amuda, A. Otuoze, and B. Olufeagba, "Current Status and Outlook of Renewable Energy Development in Nigeria," Nigerian Journal of Technology (NIJOTECH), vol. 36, no. 1, pp. 196$212,2017$.

[23] H. Yang, L. Lu, and W. Zhou, "A novel optimization sizing model for hybrid solar-wind power generation system," Solar Energy, vol. 81, no. 1, pp. 76-84, 2006.

[24] (2019, Sept.) How homer calculates the pv array power output. HOMER Energy. [Online]. Available: https://www.homerenergy.com/products/pro/docs/3.13/ howhomer_calculates_the_pv_array_power_output. html 